\title{
ASO Visual Abstract: Incidence of Recurrent Laryngeal Nerve Palsy in Robot-Assisted Versus Conventional Minimally Invasive McKeown Esophagectomy in Prone Position: A Propensity Score- Matched Study
}

Taro Oshikiri, MD ${ }^{1}$, Hironobu Goto, $\mathrm{MD}^{\mathbf{1}}$, Manabu Horikawa, $\mathrm{MD}^{1}$, Naoki Urakawa, $\mathrm{MD}^{\mathbf{1}}$, Hiroshi Hasegawa, $\mathrm{MD}^{1}$, Shingo Kanaji, MD, $\mathrm{PhD}^{1}$, Kimihiro Yamashita, MD, $\mathrm{PhD}^{1}$, Takeru Matsuda, MD, $\mathrm{PhD}^{2}$, Tetsu Nakamura, MD, $\mathbf{P h D}^{1}$, and Yoshihiro Kakeji, $\mathbf{M D}, \mathbf{P h D}^{1}$

${ }^{1}$ Division of Gastrointestinal Surgery, Department of Surgery, Graduate School of Medicine, Kobe University, Kobe, Hyogo, Japan; ${ }^{2}$ Division of Minimally Invasive Surgery, Department of Surgery, Graduate School of Medicine, Kobe University, Kobe, Hyogo, Japan

Esophagectomy with lymphadenectomy is the principal treatment for localized esophageal cancer. Conventional minimally invasive esophagectomy (C-MIE) in prone position has spread worldwide as it is less invasive. However, its efficacy remains controversial. Robot-assisted MIE (RAMIE) can have more advantages than C-MIE. Our study reported that RAMIE is superior to C-MIE in prone position in decreasing the incidence of left RLN palsy (https://doi.org/10.1245/s10434-021-10123-w).

Publisher's NoteSpringer Nature remains neutral with regard to jurisdictional claims in published maps and institutional affiliations.

DISCLOSURES The authors have no conflicts of interest or financial ties to disclose.

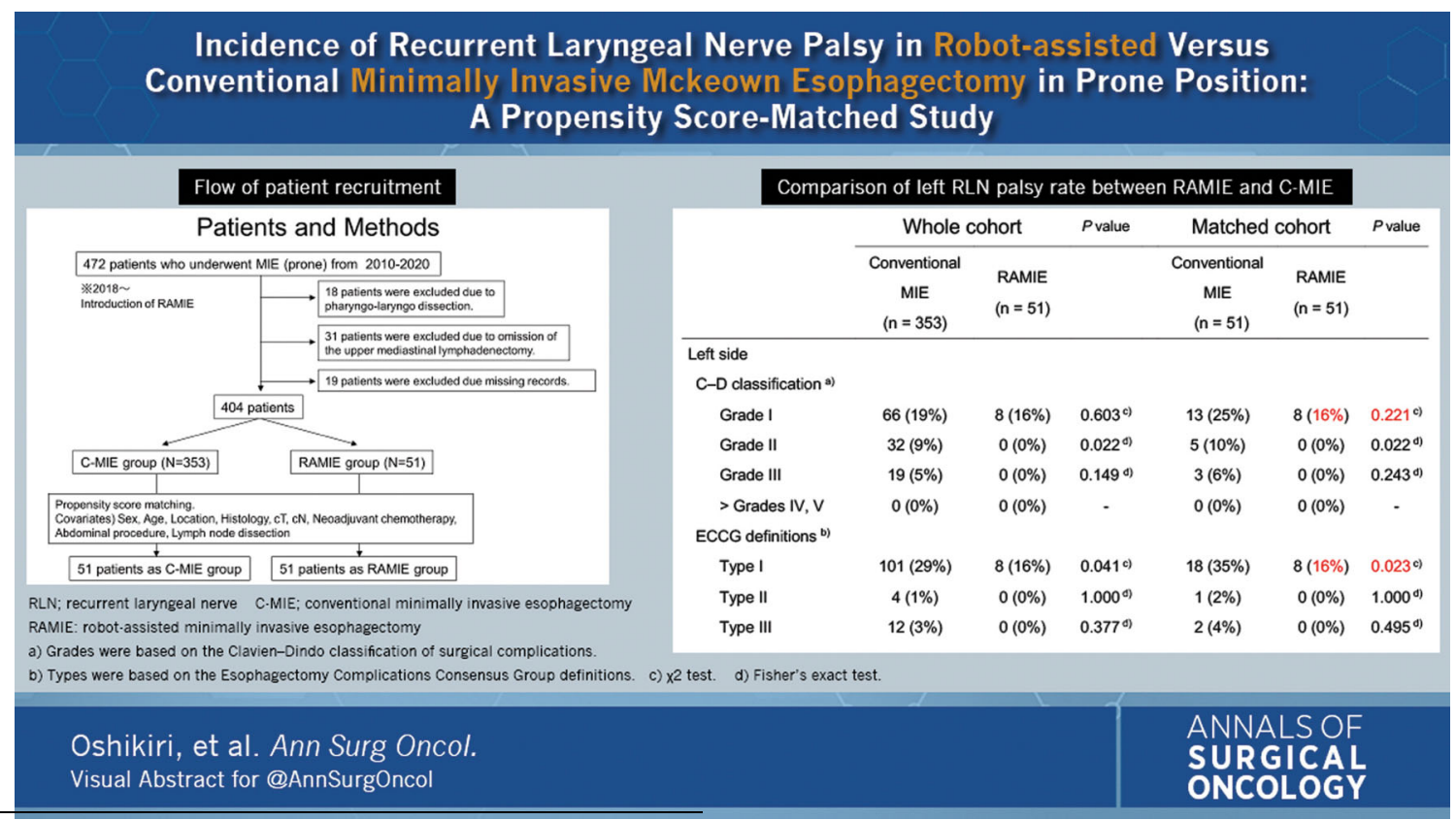

(C) Society of Surgical Oncology 2021

Published Online: 27 May 2021

T. Oshikiri, MD

e-mail: oshikiri@med.kobe-u.ac.jp 